\title{
OCCULT CERVICAL NODAL METASTASIS IN ESOPHAGEAL CANCER: PRELIMINARY RESULTS OF THREE-FIELD LYMPHADENECTOMY
}

Nasser K. Altorki, MD

David B. Skinner, MD

\begin{abstract}
The extent of lymphadenectomy for carcinoma of the thoracic esophagus remains debatable. A prospective study was initiated in August 1994 to evaluate the patterns of nodal spread after esophagectomy with three-field lymph node dissection. The hospital mortality rate was $3.3 \%$. Nodal metastases occurred in $73 \%(22 / 30)$ of patients. The most commonly affected nodal groups were the lesser curvature nodes $(57 \%)$, parahiatal nodes $(\mathbf{4 2} \%)$, and the right recurrent nodes $(35 \%)$. Cervical nodal metastasis occurred in 10 patients $(35 \%)$ irrespective of tumor location or $T$ status. The cervical field of dissection was as likely as the mediastinum to be a site of nodal disease. These findings should be considered when the operative strategy for esophageal carcinoma is planned. (J Thorac Cardiovasc Surg 1997;113:540-4)
\end{abstract}

$\mathrm{T}$ he extent of surgical resection for carcinoma of the thoracic esophagus remains the subject of controversy. Advocates of limited resections are undoubtedly influenced by current trends in the treatment of breast cancer and maintain that primary surgical therapy for esophageal cancer is, at best, of palliative benefit. ${ }^{1}$ Furthermore, most medical and radiation oncologists, dismayed by high local and distant failure rates after standard techniques of esophagectomy, have called into question the relevance of operation in the treatment of this disease. ${ }^{2,3}$ Some surgeons have practiced a more radical resection technique in which an en bloc resection of the tumor-bearing esophagus is complemented by a radical lymphadenectomy of the lower and middle mediastinum, as well as of the upper abdomen. ${ }^{4-6}$ Although the local failure rates were gratifyingly low, distant failure continued to occur in $30 \%$ to $40 \%$ of patients. ${ }^{7}$ Additionally, we observed that the cervical lymph nodes were the first site of tumor recurrence in approximately $18 \%$ of patients in whom all lymph nodes were free of cancer metastases after en bloc resections. ${ }^{7}$

From the New York Hospital-Cornell Medical Center, New York, N.Y.

Received for publication June 24, 1996; revisions requested August 21, 1996; revisions received Sept. 11, 1996; accepted for publication Sept. 12, 1996.

Address for reprints: Nasser K. Altorki, MD, New York Hospital-Cornell Medical Center, 525 E. 68th St., Room F-2212, New York, NY 10021.

Copyright (C) 1997 by Mosby-Year Book, Inc.

$0022-5223 / 97 \$ 5.00+0 \quad \mathbf{1 2 / 1 / 7 8 0 3 2}$
During the past 10 to 15 years Japanese surgeons have consistently reported a distressingly high rate of tumor recurrence in the cervical nodes and have consequently added cervical node dissection (third field) to their standard two-field radical esophagectomy. ${ }^{8}$ The preliminary and intermediate-term results of three-field lymph node dissection reported thus far have been quite enlightening and appear to offer some patients a significant survival benefit. ${ }^{9-11}$ The increased morbidity of the procedure, particularly the increased likelihood of recurrent nerve injury, delayed its immediate adoption by many European and North American centers. However, recent preliminary reports from Europe have confirmed the findings from the Far East.*

In August 1994 we initiated a prospective study to evaluate esophagectomy with three-field lymph node dissection in patients with carcinoma of the thoracic esophagus. Our primary objectives were to determine the prevalence of cervical node metastasis in a North American-based patient group and to determine whether cervical node metastasis is an early or late event in the course of the disease.

\section{Methods}

A prospective study to evaluate three-field dissection was initiated in August 1994. Patients were eligible only if the entire tumor was located within the tubular esophagus and there was no preoperative or intraoperative evidence of visceral metastasis. Tumors of the lower third of the esophagus were included only if they did not extend past

\footnotetext{
*Personal communications from A. Lerut, MD, and A. Perrachia MD, 1994
} 
Table I. Surgical procedure: right thoracotomy, laparotomy, cervicotomy

\begin{tabular}{|c|c|}
\hline Field & Nodes \\
\hline 1 & $\begin{array}{l}\text { Abdominal (parahiatal, lesser curve, left } \\
\text { gastric, splenic, hepatic) }\end{array}$ \\
\hline 2 & $\begin{array}{l}\text { Mediastinal (thoracic duct; lower, } \\
\text { middle, and upper paraesophageal; } \\
\text { subcarinal, aortopulmonary window, } \\
\text { right and left level 9) }\end{array}$ \\
\hline 3 & $\begin{array}{l}\text { Cervicothoracic (left and right re- } \\
\text { current chains, lateral and poste- } \\
\text { rior internal jugular, and supraclavicular) }\end{array}$ \\
\hline
\end{tabular}

the gastroesophageal junction. Three-field dissection was not done in patients in whom the tumor was located at or beyond the gastroesophageal junction and in those in whom resections were done for high-grade dysplasia.

Between August 1994 and April 1996, 28 patients underwent subtotal esophagectomy with three-field dissection. The three fields of nodes dissected were standardized and lymph nodes were labeled by the operating surgeon in the operating room (Table I). Data from two additional patients who underwent the procedure before the initiation date of the study were retrospectively evaluated and included in the analysis.

Surgical procedure. Twenty-nine patients underwent resection through a right lateral thoracotomy followed by repositioning and simultaneous laparotomy and neck incision. One patient with a tumor of the upper third of the thoracic esophagus had the resection done by a neck incision, a partial sternotomy, and a laparotomy. In general all patients underwent an en bloc resection as previously described whereby the tumor-bearing esophagus was resected within an envelope of tissue containing the thoracic duct posteriorly, the pericardium anteriorly, and both pleural surfaces laterally. ${ }^{12}$ After completion of the en bloc resection, the right and left recurrent nerves were exposed and lymph nodes along the course of both nerves were dissected. Lymph nodes, especially those along the right recurrent nerve, formed a continuous chain that extended through the thoracic inlet along the recurrent nerves into the cervical paratracheal region.

After closure of the thoracotomy, a laparotomy and a generous neck collar incision were done. The abdominal lymphadenectomy was done as previously described. ${ }^{12}$ In the neck the right and left recurrent nerves were exposed and the remainder of the adjacent chain of nodes removed. The clavicular head of the sternoduodenomastoid muscle was divided exposing the infraomohyoid compartment. The nodes posterior and lateral to the internal jugular vein and the supraclavicular and infraomohyoid nodal basins were then excised. The dissection of the nodes in the superior mediastinum and the neck extended the operative time by approximately 1 hour.

Patients were generally kept in the recovery room for 24 hours, sedated and with mechanical ventilation of the lungs, and extubated the morning after the procedure.
Table II. Clinical features $(n=30)$

\begin{tabular}{lrr} 
& $N$ & $\%$ \\
\hline Cell type & & \\
$\quad$ Squamous & 15 & \\
adenocarcinoma & $15^{\text {** }}$ & \\
Tumor location & & 6.5 \\
$\quad$ Upper third & 2 & 26.0 \\
Middle third & 8 & 67.5 \\
Lower third & 20 & \\
pTNM stage & & \\
I & 3 & \\
II & 11 & \\
III & 16 &
\end{tabular}

*All located in lower third.

Table III. Complications $(n=12)$

\begin{tabular}{|c|c|c|}
\hline & $N$ & $\%$ \\
\hline Pulmonary & 11 & 36 \\
\hline Bronchorrhea & 5 & \\
\hline Pneumonia & $1^{*}$ & \\
\hline Intubation $>72 \mathrm{hr}$ & 5 & \\
\hline Leaks & 6 & 20 \\
\hline Gastric tip neurosis & 3 & \\
\hline Anastomotic leak & 3 & \\
\hline Recurrent nerve injury & 2 & 6 \\
\hline Empyema & 1 & \\
\hline Delirium tremens & 1 & \\
\hline
\end{tabular}

*Hospital death.

Oral intake of liquids was begun on the fifth postoperative day and advanced to a general diet after the integrity of the anastomosis was confirmed by a barium swallow on the sixth or seventh postoperative day. Twenty-two patients $(73 \%)$ were discharged by postoperative day 12 .

\section{Results}

There were 19 male and 11 female patients with a median age of 61 years (range 40 to 75 ). Tumor location, cell types, and final tumor stages are shown in Table II. There was one hospital death (including death within 30 days of the procedure) for an operative mortality rate of $3.3 \%$. Death occurred as a result of bilateral antibiotic-resistant Pseudomonas pneumonia that developed within 72 hours after operation. Twenty-two complications occurred in 12 patients (1.8 per patient) and are detailed in Table III. Pulmonary complications were most common, including bronchorrhea that was significant in five patients and necessitated repeated bronchoscopy. Although recurrent nerve injury occurred in two patients it was permanent in only one and neither required tracheostomy. 
Table IV. T status and cervical node metastasis

\begin{tabular}{ccc}
\hline$T$ status & All patients & Patients with CNM \\
\hline 1 & 5 & 2 \\
2 & 5 & 1 \\
3 & 20 & 7 \\
\hline
\end{tabular}

CNM, Cervical node metastasis.

Patterns of spread. A total of 1801 lymph nodes were resected, or approximately 60 nodes per case. Twenty-two patients (73\%) had nodes positive for disease. The most commonly affected nodal groups were, in order of frequency, the lesser curvature nodes $(57 \%)$, the parahiatal nodes $(42 \%)$, and the right recurrent nerve nodes $(35 \%)$. Five patients had only one positive node, 7 patients had 2 to 5 , and $10 \mathrm{had}$ more than 5 nodes positive for disease. A single field was affected by nodal metastasis in 10 patients ( 6 abdominal only, 2 cervical only, 2 mediastinal only). Two fields were involved in 8 patients and metastases were present in all three fields in 4 patients. Overall the most commonly involved field was the abdominal (18 patients) followed by the cervical and mediastinal fields in 10 patients each.

Prevalence of cervical node metastasis. Ten patients $(30 \%)$ had metastases to the cervical nodes (recurrent or deep cervical nodes, or both). Six patients had squamous cell carcinoma and four had adenocarcinoma. Cervical node metastasis was seen in $6(30 \%)$ of 20 patients with lower-third tumors (4/15 adenocarcinoma and 2/5 squamous cell tumors). Three of 8 patients and 1 of 2 patients with middle and upper-third squamous cell cancers, respectively, had cervical node metastasis. Ten patients had negative nodes in the abdomen and mediastinum, and 2 of these had positive nodes in the neck. Among patients with squamous cell carcinoma, 2 had metastasis in the cervical nodes only, whereas in no patient with adenocarcinoma was metastasis present in the cervical nodes alone.

Are cervical node metastases early events? To determine the relative stage at which metastasis to the cervical nodes occurs, we attempted to correlate the frequency of cervical node metastasis with the number of positive nodes and the depth of tumor penetration. The results are shown in Tables IV and $\mathrm{V}$. Interestingly, metastases to the cervical nodes were equally prevalent among $\mathrm{T} 1$ and $\mathrm{T} 3$ tumors. Additionally, among five patients with only one node positive for disease, the cervical region was the site of metastasis in two patients and was thus equally likely to be the sole site of spread as the
Table V. Number of nodes and cervical node metastasis

\begin{tabular}{ccc}
\hline No. of positive nodes & All patients & Patients with CNM \\
\hline 1 & 5 & 2 \\
$2-5$ & 7 & 3 \\
$>5$ & 10 & 5 \\
\hline
\end{tabular}

CNM, Cervical node metastasis

perigastric or periesophageal region. These data suggest to us that spread to that nodal basin may occur at a relatively early stage of tumor development.

\section{Discussion}

To the best of our knowledge this is the first published report on the prevalence of metastasis to the cervical nodes in adenocarcinoma of the esophagus. Notwithstanding the small number of patients in this study, it appears that cervical node metastasis occurs with similar frequency in adenocarcinoma as in squamous tumors.

Our data, as well as those of others, ${ }^{9-11,13}$ would indicate that at least one third of patients who undergo an en bloc or standard esophagectomy would not be free of disease at the conclusion of the operative procedure. Although some might argue that recurrence is inevitable under such circumstances, it is clear that the role of surgical resection is, at best, doubtful in the setting of an incomplete resection.

The $30 \%$ prevalence of preoperatively unsuspected cervical nodal metastases is in accordance with the plethora of reports from Japanese and European surgeons. ${ }^{11,13 *}$ In Europe both Lerut and Perrachia have reported similar results with an incidence of cervical nodal metastasis in patients who underwent operation in excess of $30 \%$ (personal communications). In our patients the addition of the cervical field of dissection would have resulted in changing the TNM staging in at least four patients in whom metastases were present in the deep cervical nodes: two from stage III to IV (lymph), one from stage I to IV (lymph), and one from stage IIA to III (data not shown). If one were to consider disease in the recurrent nerve nodes as extrathoracic metastasis, then six additional patients would have been assigned a higher stage.

In 1986, Tanabe and associates ${ }^{14}$ reported on the patterns of lymph flow from the esophagus after

*A. Lerut, MD, personal communication, 1994. 
injection of technetium-labeled rhenium colloid into the esophageal wall. Uptake was routinely detected by scintillation counting in the upper mediastinal and cervical nodes and in the left gastric nodes after injection in the midthoracic esophagus. Our data seem to support the concept that spread to the upper mediastinal and cervical nodes may occur at a relatively early stage of esophageal carcinogenesis. In fact, the cervical field was involved with metastatic disease with a similar frequency to that in the mediastinal nodal basin. Metastatic spread to the cervical lymph nodes occurred at all levels of tumor penetration into the esophageal wall. Furthermore, when metastasis was present in only one lymph node, the cervical region was as likely as the mediastinal or the perigastric regions to be the site of spread.

Debate continues regarding the efficacy of lymph node dissection in improving survival and will undoubtedly extend to the concept of three-field lymph node dissection. Although this study cannot at this time predict a survival advantage for this technique, several authors have reported a possible salutary effect. Kato and coworkers ${ }^{9}$ reported in 1991 a $30 \%$ 5 -year survival in patients in whom the cervical nodes were the only site of cancer spread. Matsubara and coworkers ${ }^{13}$ have also previously reported similar observations in a large number of patients with squamous cell cancer of the thoracic esophagus. Among 29 patients in that study with only one positive node, $60 \%$ had the metastasis in the cervical region and $32 \%$ in the perigastric region. Survival in this "favorable" group was $75 \%$ and $68 \%$ at 3 and 5 years, respectively. With the use of subtotal esophagectomy and three-field lymph node dissection Baba and coworkers ${ }^{11}$ reported a 5-year survival of $30 \%$ in patients with stage III disease. Akiyama and associates ${ }^{10}$ reported their experience with this technique with a similar 5 -year survival for patients with stage III disease. These compelling data may force a complete reappraisal of the role of extended lymphadenectomy in the treatment of esophageal carcinoma.

The continued poor outcome of the majority of patients with carcinoma of the thoracic esophagus has prompted a barrage of trials of preoperative chemotherapy or chemoradiotherapy in an attempt to improve survival. ${ }^{15-17}$ Unfortunately to date no randomized trial has documented a survival benefit of preoperative therapy compared with operation alone. ${ }^{18,19}$ A widely quoted randomized trial by Herskovitz and coworkers ${ }^{3}$ found that chemoradiotherapy is superior to radiotherapy alone with a 5-year survival of approximately $30 \%$. However, the local failure rate in that trial was at least $34 \%$, which calls into question the adequacy of chemoradiation as a primary modality of local control. Whereas the need for effective systemic agents that decrease distant failures is clear to most investigators, the role of an optimal modality of local control is not fully appreciated. Only a clear understanding of the patterns of local spread would allow one to develop an effective method of local control.

\section{REFERENCES}

1. Orringer MB. Ten year survival after esophagectomy for carcinoma: surgical triumph or biologic variation? Chest 1989;96:970-1.

2. Leichman L, Herskovic A, Leichman CG, et al. Nonoperative therapy for squamous-cell cancer of the esophagus. J Clin Oncol 1987;5:365-70.

3. Herskovitz A, Martz K, Sarraf M, et al. Combined chemotherapy and radiotherapy compared with radiotherapy alone in patients wtih cancer of the esophagus. $\mathrm{N}$ Engl $\mathrm{J}$ Med 1992;326:67-72.

4. Hagen JA, Peters JH, DeMeester TR. Superiority of extended en bloc esophagectomy for carcinoma of the lower esophagus and cardia. J Thorac Cardiovasc Surg 1993;106: 850-8.

5. Lerut T, De Leyn P, Coosemans W, et al. Surgical strategies in esophageal carcinoma with emphasis on radical lymphadenectomy. Ann Surg 1992;216:583-90.

6. Siewert JR, Holscher AH, Dittler HJ. Peroperative staging and risk analysis in esophageal carcinoma. Hepatogastroenterology 1990;37:382-7.

7. Altorki NA, Girardi L, Skinner DB. Extended resections of the thoracic esophagus and cardia. Diseases of the esophagus: proceedings of the sixth ISDE World Congress. Current Opinion in General Surgery. Philadelphia: Current Science, August 23-26, 1995.

8. Isono $\mathrm{K}$, Onoda $\mathrm{S}$, Okuyama $\mathrm{K}$, et al. Recurrence of intrathoracic esophageal cancer. Jpn J Clin Oncol 1985; 15:49-60.

9. Kato $H$, Tachimori $Y$, Watanabe $H$, et al. Lymph node metastasis in thoracic esophageal carcinoma. J Surg Oncol 1991;48:106-11.

10. Akiyama $H$, Tsurumaru $M$, Udagawa $H$, et al. Radical lymph node dissection for cancer of the thoracic esophagus. Ann Surg 1994;220:364-72.

11. Baba M, Aikou T, Yoshinaka H, et al. Long-term results of subtotal esophagectomy with three-field lymphadenectomy for carcinoma of the thoracic esophagus. Ann Surg 1994;219:31-6.

12. Altorki NA, Skinner DB. En bloc esophagectomy: the first 100 patients. Hepatogastroenterology 1990;37:360-3.

13. Matsubara T, Mamoru U, Yanagida O, et al. How extensive should lymph node dissection be for cancer of the thoracic esophagus? J Thorac Cardiovasc Surg 1994;107: 1073-8.

14. Tanabe G, Baba M, Kuroshima K, et al. Clinical evaluation of esophageal lymph flow system based on the RI uptake of 
removed regional lymph nodes following lymphoscintigraphy. J Jpn Surg Soc 1986;87:315-23.

15. Naunheim K, Petruska P, Roy T, et al. Preoperative chemotherapy and radiotherapy for esophageal carcinoma. J Thorac Cardiovasc Surg 1992;103:887-95.

16. Forastiere A, Orringer M, Perez-Tamayo C, et al. Preoperative chemoradiation followed by transhiatal esophagectomy for carcinoma of the esophagus: final report. J Clin Oncol 1993;11:1118-23.

17. Urba SG, Orringer MB, Perez-Tamayo C, et al. Concurrent preoperative chemotherapy, radiation therapy in localized esophageal adenocarcinoma. Cancer 1992;69:285-91.

18. Roth JA, Pass HU, Flanagan MM, et al. Randomized clinical trials of preoperative and postoperative adjuvant chemotherapy with cisplatin, vindesine and bleomycin for carcinoma of the esophagus. J Thorac Cardiovasc Surg 1988;96:242-8.

19. Schlag P. Randomisierte Studie zur praoperativen Chemotherapie beim Plattenepithelcarcinom des Oesophagus. Chirurg 1992;63:709-14.

\section{Availability of Journal back issues}

As a service to our subscribers, copies of back issues of The Journal of Thoracic and Cardiovascular Surgery for the preceding 5 years are maintained and are available for purchase from Mosby at a cost of $\$ 15.00$ per issue until inventory is depleted. The following quantity discounts are available: $25 \%$ off on quantities of 12 to 23 , and one third off on quantities of 24 or more. Please write to Mosby-Year Book, Inc., Subscription Services, 11830 Westline Industrial Drive, St. Louis MO 63146-3318, or call 800-453-4351 or 314-453-4351 for information on availability of particular issues. If unavailable from the publisher, photocopies of complete issues may be purchased from UMI, 300 N. Zeeb Rd., Ann Arbor, MI 48106, 313-761-4700. 